\title{
GASTRITIS AND HELICOBACTER PYLORI IN CHILDREN - PRIMARY AND SECONDARY ENDOSCOPIC DIAGNOSIS
}

\author{
V.V. Lupu ${ }^{1}$, Gabriela Paduraru ${ }^{1}$, Ancuta Ignat ${ }^{1}$, Eliza Tighici-Saizu ${ }^{2}$, \\ Claudia Olaru ${ }^{1}$, Nicoleta Gimiga ${ }^{1}$, Angelica Cristina Marin ${ }^{1}$, Cornelia Savescu ${ }^{1}$, \\ Ioana Florea ${ }^{1}$, Marin Burlea ${ }^{1}$

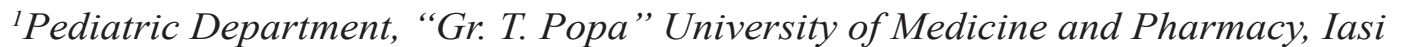 \\ ${ }^{2}$ Emergency County Hospital, Vaslui
}

\begin{abstract}
The infection with Helicobacter pylori (H pylori) represents an important issue of public health. Aim. Establishing the prevalence of $H$. pylori infection in children and presenting the cases according to the gastritis type by performing upper digestive endoscopies.

Material and method. The retrospective study referred to a period of 5 years and included 1269 children evaluated by upper endoscopy to establish the $H$. pylori infection rate.

Results. The frequency of $H$. pylori in the case of acute gastritis was significantly more reduced (34.78\%) than in the case of chronic gastritis (54.94\%). Referring to the 10 types of gastritis, the most frequent ones are purpuric $(43.66 \%)$, nodular purpuric $(25.93 \%)$ and nodular antral $(15.84 \%)$. At the other end, atrophic and hypertrophic gastritis were positioned. The most frequent associations pointed out endoscopically are those with $1^{\text {st }}$ degree esophagitis $-51.6 \%$, duodenitis $-45.07 \%$ and purpuric duodenitis $-24.74 \%$.

Conclusions. The $H$. pylori infection is the most frequent etiologic factor for chronic gastritis $(54.94 \%)$. The early identification of the infection is essential to destroy the bacteria and to prevent the development of various types of gastritis that are later on endoscopically identified.
\end{abstract}

Keywords: gastritis, H. pylori, upper endoscopy, child

\section{INTRODUCTION}

Helicobacter pylori (H. pylori) is one of the most frequent chronic bacterial infections worldwide and, at the time being, it is estimated that almost half of the world's population is infected with this bacteria $(1,2)$. H. pylori causes active chronic gastritis in both adults and children (3) and it is associated with peptic ulcer, atrophy, intestinal metaplasia and gastric cancer in adults (4).

The role of $H$. pylori was demonstrated in the pathology of gastritis and the positive correlation of the infection with the prevalence of gastritis and, subsequently, with the pathology characteristic to the adult. The early identification of the infection is the key element in destroying the bacteria and in preventing the apparition of various types of gastritis that are later on endoscopically identified.

\section{AIM}

Establishing the frequency of $H$. pylori infection in pediatric population and identifying the cases according to the characteristics and the type of gastritis at a significant group of children with specific symptoms, by performing superior digestive endoscopy.

\section{MATERIAL AND METHOD}

The retrospective study referred to a period of 5 years and included 1269 children aged between 1 -18 years old diagnosed with gastritis, after establishing the medical history of the patient and performing the clinical and laboratory examination in a pediatric gastroenterology regional center in northeast Romania. 
The technique used for performing upper endoscopy:

- Children were examined after 8-10 hours of digestive repose, while young children (under 4 years old) after 6 hours of digestive repose.

- At younger children, less than 10 years old, general anesthesia with OTI was performed, the propofol dose being of $2 \mathrm{mg} / \mathrm{kg}$.

- During the study, for sedating the patients were used: Dormicum, dose 0.15- $0.20 \mathrm{mg} /$ $\mathrm{kg}$ and Midazolam, dose 0.1-0.2 mg/kg, iv.

- The patients were positioned on their left side, with their head in semi flexion and knees flexed.

- In the oral cavity, between the dental arches an oral piece was introduced for avoiding the endoscope during the entire medical examination.

Endoscopy allows the examination of the segments seen and the extraction of several biopsies of the gastric mucosa in the antral region $(2 \mathrm{~cm}$ around the pylorus) and in the fundic region for pointing out the presence of $H$. pylori.

The presence of the bacteria is underlined by either direct examination, culture or by analyzing the activity of urease.

Some of the patients were serologically tested for detecting the IgG type anti $H$. pylori antibodies and salivary tests were performed as well.

From the study were excluded the patients who came for upper endoscopy, for the second time, to confirm the eradication of $H$. pylori. Another criterion for exclusion was the previous consumption of nonsteroidal anti-inflammatory drugs.

\section{RESULTS}

Relying on the Sydney system which allows the identification of three types of gastritis, which are seen as clinical morphological entities: acute gastritis, chronic gastritis, special gastritis, we have focused on the frequency of this disorder in the group taken into consideration. A high frequency of the cases of acute gastritis (68.67\%) was found, while the cases of chronic gastritis represented only $31.13 \%$.

Although more frequent, in the case of acute gastritis, the frequency of Helicobacter pylori was significantly smaller (34.78\%), if we compare it to that in the case of chronic gastritis (54.94\%) (Table 1).

The analysis demonstrated the significant relationship between Helicobacter pylori and chronic gastritis $\left(\chi^{2}=45.66, \mathrm{r}=-0.539, \mathrm{p}<<0.05,95 \% \mathrm{CI}\right)$.

After the upper endoscopy, the distribution of the cases according to the type of gastritis pointed
TABLE 1. Assessing the association of Helicobacter pylori vs. gastritis type

\begin{tabular}{|l|c|c|c|}
\hline \multirow{2}{*}{ Gastritis } & \multicolumn{2}{|c|}{ Helicobacter pylori } & \multirow{2}{*}{ Total } \\
\cline { 2 - 3 } & with HP & without HP & \\
\hline \multirow{2}{*}{ Acute } & 304 & 570 & \multirow{2}{*}{$\mathbf{8 7 4}$} \\
\cline { 2 - 3 } & $34.78 \%$ & $65.22 \%$ & \\
\hline \multirow{2}{*}{ Chronic } & 217 & 178 & \multirow{2}{*}{395} \\
\cline { 2 - 3 } & $54.94 \%$ & $45.06 \%$ & \\
\hline Total & $\mathbf{5 2 1}$ & $\mathbf{7 4 8}$ & $\mathbf{1 2 6 9}$ \\
\hline
\end{tabular}

out a higher number of cases of purpuric gastritis $(43.66 \%)$, nodular purpuric gastritis $(25.93 \%)$ and nodular antral gastritis (15.84\%). On the other hand, aphthous nodular gastritis $(0.16 \%)$, atrophic gastritis $(0.24 \%)$ and hypertrophic gastritis $(1.65 \%)$ recorded very low frequencies. Frequencies below $10 \%$ were recorded for erosive gastritis $(4.73 \%)$, diffuse gastritis $(4.02 \%)$ and erosive hemorrhagic gastritis $(4.02 \%)$.

The types of gastritis were also analyzed considering whether they were acute or chronic (Fig. 1).

After the upper endoscopy, other pathologies were also identified at the level of the esophagus, stomach or duodenum (Fig. 2).

The most frequent secondary diagnosis (at endoscopy) was $1^{\text {st }}$ degree esophagitis (51.6\%), being followed by diffuse duodenitis (47.07\%), purpuric duodenitis $(24.74 \%)$ and $2^{\text {nd }}$ degree esophagitis $(23.17 \%)$.

The upper endoscopy was performed without any major complications except for sore throat that was self-limited.

\section{DISCUSSIONS}

In order to perform the upper endoscopy, the main indications were recurrent abdominal pains, upper digestive hemorrhage, epigastric pains, recurrent vomiting.

Recurrent abdominal pain refers to episodes of abdominal pain which is severe enough to affect the daily activity of a child. It is demonstrated by three or more bouts in at least a three-month period (5).

In unselected samples, infected children do not report abdominal pain more often than non-infected children (6).

It is generally accepted that $H$. pylori infection is the main etiologic factor for gastritis and peptic ulcer (7). The prevalence of $H$. pylori infection differs from one region to the other and it is also related to age. In the United States, the children positive for $H$. pylori aged under 10 represent less than $5 \%$, while the adults of 20 and over 60 represent $10 \%$ and $60 \%$ respectively (8). In Japan, the preva- 


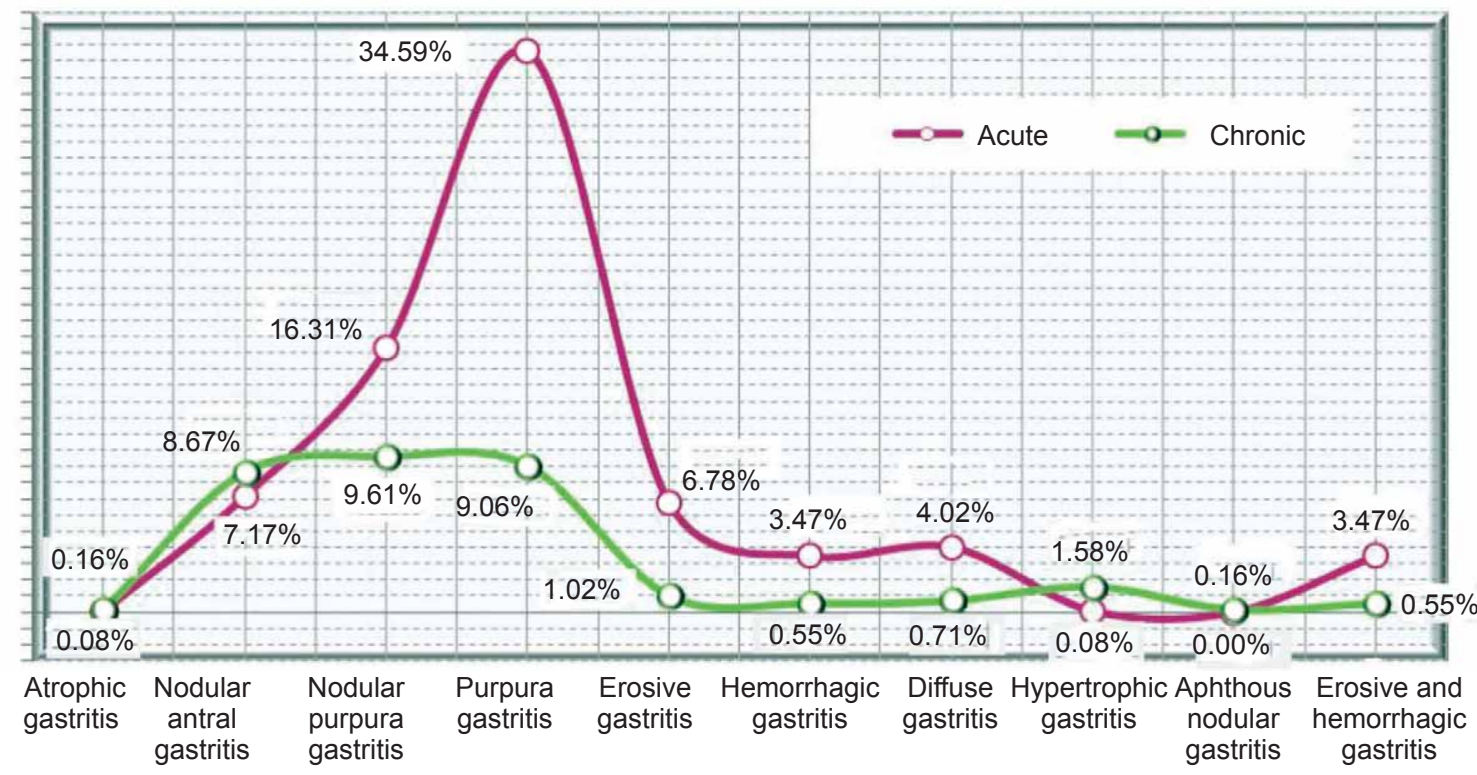

FIGURE 1. The distribution of cases according to the characteristics and the type of gastritis

\section{Secondary endoscopy diagnosis}

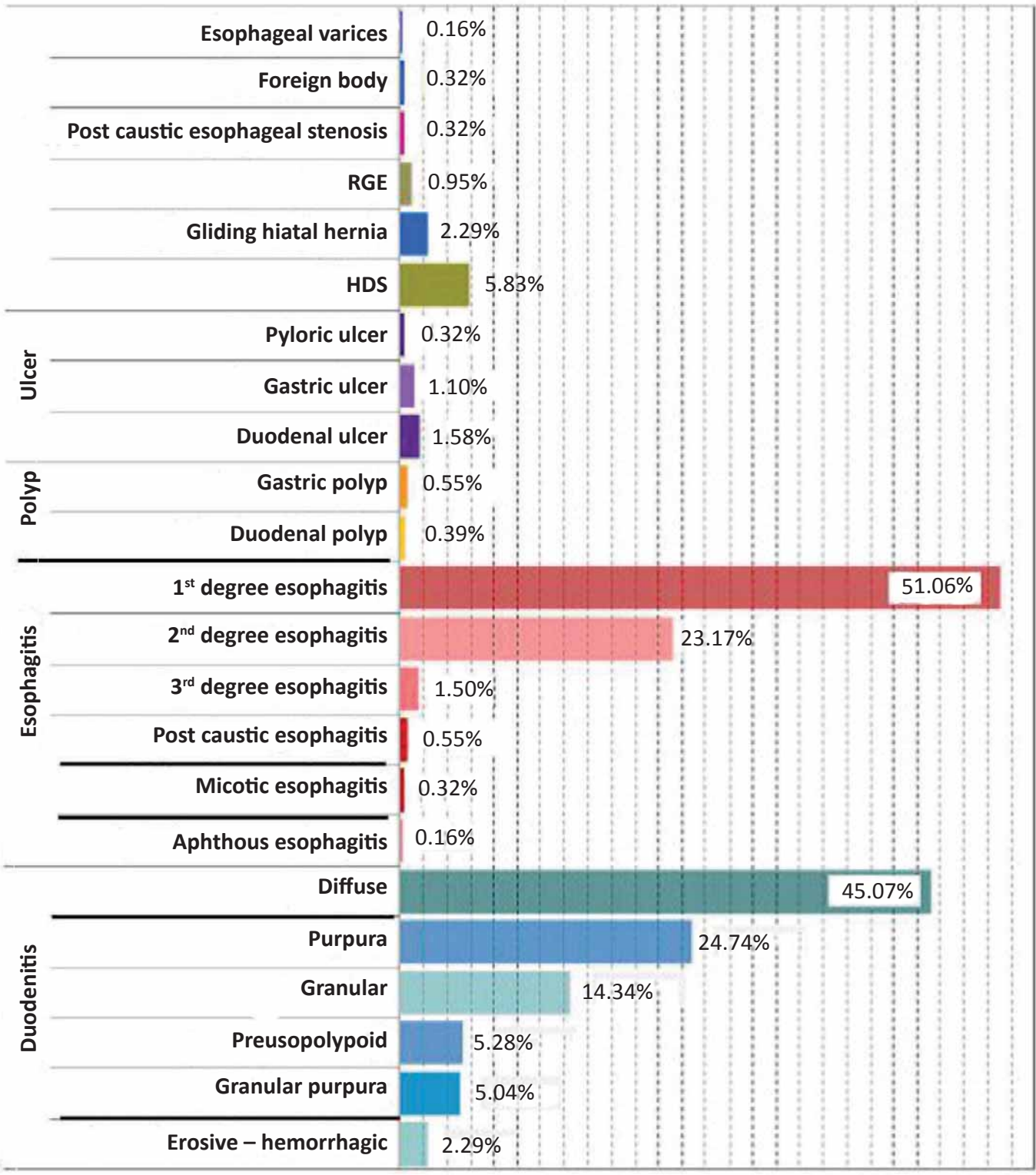


lence of $H$. pylori infection at people aged between 15 and 19 years old represented 29\% (9). In Italy, the children under 12 who presented H. pylori infection represented 34\% (10). In Bangladesh, Mahalanabis et al. studied 469 children aged between 6 and 9 years old and noticed that $H$. pylori infection was present in $84 \%$ of the cases (11). The present study indicates an average result, $34.78 \%$ for acute gastritis and $54.94 \%$ for chronic gastritis.

Observing a group of 275 children aged between 1 and 15 who presented various gastrointestinal symptoms resulted that the $H$. pylori infection was present in $23.6 \%$ of the cases, information which suggested that $H$. pylori infection represents a problem for that particular area and all the children with gastrointestinal dysfunctions and all the members of the family should be examined (12).

In a study performed on 328 patients diagnosed with $H$. pylori infection, nodular gastritis was the most frequent one (50.6\%) (13).

For the 1269 children included in the study, the distribution of the cases according to the type of gastritis indicates more cases of purpuric gastritis $(43.66 \%)$, nodular purpuric gastritis $(25.93 \%)$ and nodular antral gastritis (15.84\%).

A retrospective study performed on a group of 206 children focused on the relation between H. pylori infection and the erosive reflux disease in children. The prevalence of erosive esophagitis equaled $23.8 \%$ at the patients with $H$. pylori infection and
$41.3 \%$ at those not infected. Thus, no significant associations were identified between $H$. pylori infection and erosive esophagitis, and it did not significantly influence the severity of the esophagitis (14).

Findings of upper endoscopy in a 2 year prospective study in 150 children were represented by normal 24 (16\%), hiatal hernia 30 (20\%), different grades of esophagitis 60 (40\%), esophagial erosion $39(26 \%)$, gastric erythema $51(34 \%)$, nodular gastritis $45(30 \%)$, gastric ulcer $9(6 \%)$, duodenal ulcer $3(2 \%)(15)$.

In this study, the fact that $1^{\text {st }}$ degree esophagitis resulted to be the most frequent secondary endoscopic diagnosis could not be directly related to H. pylori infection.

\section{CONCLUSIONS}

H. pylori infection is the most frequent etiologic factor of chronic gastritis (54.94\%); referring to the 10 types of gastritis, the most frequent ones are purpuric, nodular purpuric and nodular antral, the rarest are the atrophic and hypertrophic gastritis.

The early identification of the infection represents the key factor in destroying the bacteria and in preventing the apparition of various types of gastritis, that are later on endoscopically identified.

The most frequently associations pointed out endoscopically are those with $1^{\text {st }}$ degree esophagitis, duodenitis and purpuric duodenitis.

\section{$\overline{\text { REFERENCES }}$}

1. Sherman P.M. Appropriate strategies for testing and treating Helicobacter pylori in children: when and how? Am J Med. 2004; 117 Suppl 5A:30S-35S.

2. Kato S., Sherman P.M. What is new related to Helicobacter pylori infection in children and teenagers? Arch Pediatr Adolesc Med. 2005; 159:415-421.

3. Hassall E., Dimmick J.E. Unique features of Helicobacter pylori disease in children. Dig Dis Sci1991; 36:417-23.

4. Hansson L.E., Nyren O., Hsing A.W., et al. The risk of stomach cancer in patients with gastric or duodenal ulcer disease. N Engl J Med 1996; 335:242-9.

5. Apley J. Recurrent abdominal pain. Br J Clin Pract. 1959; 13:586-7.

6. Bode G., Rothenbacher D., Brenner H., Adler G. Helicobacter pylori and abdominal symptoms: a population-based study among preschool children in southern Germany. Pediatrics 1998; 101:634-37.

7. Suerbaum S., Michetti P. Helicobacter pylori infection. N Engl J Med. 2002; 347: 1175-1186.

8. Meyer B., Werth B., Beglinger C., Dill S., Drewe J., Vischer W.A., et al. Helicobacter pylori infection in healthy people: a dynamic process? Gut. 1991; 32:347-50.

9. Yamashita Y., Fujisawa T., Kimura A., Kato H. Epidemiology of Helicobacter pylori infection in children: a serologic study of the Kyushu region in Japan. Pediatr Int. 2001; 43:4-7.

10. Biselli R., Fortini M., Matricardi P.M., Stroffolini T., D’Ameli R. Incidence of Helicobacter pylori infection in a cohort of Italian military students. Infection. 1999; 27:187-91.

11. Mahalanabis D., Rahman M.M., Sarker S.A., Bardhan P.K., Hildebrand P., Beglinger C., et al. Helicobacter pylori infection in the young in Bangladesh: prevalence, socioeconomic and nutritional aspects. Int J Epidemiol. 1996; 25:894-8.

12. Abdullah Ceylan, Ercan Kırımi, Oğuz Tuncer, Kürşat Türkdoğan, Sevil Arıyuca, and Nesrin Ceylan. Prevalence of Helicobacter pylori in Children and Their Family Members in a District in Turkey. J Health Popul Nutr. 2007 December; 25(4): 422-427.

13. Hong Koh, Tae-Woong Noh, Seoung-Yon Baek, and Ki-Sup Chung. Nodular Gastritis and Pathologic Findings in Children and Young Adults with Helicobacter pylori Infection. Yonsei Med J. 2007 April 30; 48(2): 240-246.

14. Emiroglu H.H., Sokucu S., Suoglu O.D., Gulluoglu M., Gokce S. Is there a relationship between Helicobacter pylori infection and erosive reflux disease in children? Acta Paediatr. 2010 Jan; 99(1):121-5.

15. Farzaneh Motamed, Sayna Norouzi, Mehri Najafi, Ahmad Khodadad, Fatemeh Farahmand, Sara Mossahebi, and Giv Heidari-Bateni. Upper Endoscopic Findings in Children with Recurrent Abdominal Pain: High Prevalence of Hiatus Hernia. Iran J Pediatr. Sep 2012; 22(3): 309-313. 